\title{
Development of Personal Selling Standard and Improvement of MSME X's Wedding Promotion Material
}

\author{
Jamal Radifan ${ }^{1}$ and Hasnul Suhaimi ${ }^{1}$
}

\begin{abstract}
Currently, the type of industry that still growing is the wedding industry. The increasing number of marriages in Indonesia contributes to the need for wedding services. MSME $X$ owners seek the opportunities needed to provide services and various options for the needs of marriage. MSME $X$ is currently held in Jakarta and Bekasi. This study discusses the business coaching process report MSME $X$ personal selling and improving promotional materials in the form of brochures to attract consumers. The challenge in selling wedding services is that consumers cannot feel or touch services first. Preliminary analysis shows that salesperson use brochures as sales aids, there are differences in the level of sales competency among marketing employees, so personal selling activities are not optimal and affect the company's sales targets. Primary data collected through in depth interviews and observations, while secondary data is obtained from owners, the internet, and management books. The collected data will be analyzed using qualitative methods. This research focuses on the formulation of personal selling standards, and improvement of promotional materials as a tool for salesperson in conducting sales of wedding services. The results of this business coaching process explain the steps that can be used to conduct wedding service sales and the effect of improving promotional materials that help resolve limitations in the marketing aspects of MSME X.
\end{abstract}

Keywords-Business Coaching, MSME, Personal Selling Standard, Promotional Materials, Wedding Industry.

\section{INTRODUCTION}

Micro, Small and Medium Enterprises (MSMEs) are the largest number of business groups and play an important role in the Indonesian economy. MSMEs are not much affected by the monetary crisis that occurred in Indonesia. After the impact of the crisis, the number of small microenterprises has actually increased[1]. The research conducted by Obi, et al. (2018)[2], prove that small and medium enterprises significantly encourage economic growth, especially in developing countries. Given the important role of MSMEs in developing countries' economic growth, the role of the government in strengthening MSMEs and making them more successful is very important. Ndiaye et al, (2018)[3], reported the importance of MSMEs in shaping theeconomic landscape of developing countries, this could be the basis for the

\footnotetext{
${ }^{1}$ Jamal Radifan and Hasnul Suhaimi are with Magister of Management, Universitas Indonesia, Jakarta, 16424, Indonesia. E-mail: jamal.radifan@gmail.com; hasnuls@gmail.com.
}

government in creating programs to create MSMEs and motivating existing MSMEs to maintain performance and improve growth.

MSME X has operated four ballrooms in Jakarta and Bekasi that offer wedding services. The increasing number of marriages is an opportunity for the company's business continuity. Data from the Badan Pusat Statistik (2018) [4], shows an increase in national marriage rates during 2016 to 2017, the number of marriages in the DKI Jakarta province in 2017 reached 56,355 and marriages in West Java reached 400,311 .

The use of wedding services in MSME X in recent years shows growth. Even though it grows every year, a company engaged in property rentals such as MSME X has a fairly low occupancy rate. The occupancy rate of MSME $\mathrm{X}$ wedding services per year has not reached $50 \%$ and meets the target of MSME X owners.

Based on interviews with Rika as the owner, marketing activities were carried out by MSME $\mathrm{X}$ including the use of sales promotions and through personal selling carried out by marketing employees. To attract attention and offered value to customers, MSME X uses advertising media, one of which uses brochures. Brochures are used to attract consumers' attention and convince consumers to make purchasing decisions [5]. But the brochure of MSME $\mathrm{X}$ offers does not encourage consumers to purchase services offered by marketing employees.

Wedding services offered by MSME X are included in the category of people processing services. According to Lovelock \& Wirtz, (2016)[6], to receive this type of service category customers must physically enter the service system. According to Antczak \& Sypniewska (2017)[7], personal selling has a special role in the service provider industry. The role that must be done is to build relationships based on trust, because the customer cannot feel or touch the service first. MSME X assigns marketing employees to interact with prospective customers with the aim of making presentations, answering questions and to get orders, this activity is carried out through marketing offices, telephone and messaging applications on mobile phones.

Constraints owned by MSME X include promotional material not attractive to consumers and marketing employees has limited skills in the sales process to consumers, this is because the company does not have a 
personal selling standard for marketing employees in conducting services and delivering messages when communicating and making sales to consumers and do not have promotional material to attract consumers to make purchases.

Therefore, this research through business coaching program aims to develop operational standards in conducting personal selling and improve the appeal of wedding service promotion materials so as to help resolve the limited sales skills experienced by marketing employees and appeal of MSME X's promotion material

\section{LITERATURE REVIEW}

\section{A. Personal Selling}

The role of communication in the service business is not only through media advertising, social media, public relations and sales forces but must be seen more broadly such as location and atmosphere of service facilities, company design features such as consistent use of color and graphic elements, employee appearance and behavior and website design. All of these elements contribute to the impression in the customer's mind, strengthen or conflict with the specific content of the communication message conveyed by the company. Submitting messages to consumers needs to determine the content, structure, and style of messages that will be communicated, how they are presented, and the media that is best suited to reach the intended consumers[6].

Personal selling involves direct contact between buyers and sellers, either face to face or through some form of communication such as telephone and internet. Companies use the internet to improve customer relations, internet use is designed to be a complementary tool in personal selling to increase sales[5].

Kotler, et al (2016)[8], describes the main steps that can be taken to implement personal selling practices effectively in selling products as follows: prospective customers and qualifications, pre-approaches, presentations and demonstrations, dealing with customer objections, closure, follow-up and maintaining relationships. According to Antczak \& Sypniewska (2017)[7], Knowledge, advice and professionalism of sales staff rank more than the industry related to goods. There are several differences in the stages of effective personal selling practices in the service provider industry, including:

1. Steps to attract customers, at this stage the sales staff explained the benefits of the company's services and the explanation of the service process that will be received by the customer when using the services offered by the company.

2. Conversation/meeting, at this stage the salesperson needs to know what the customer needs, who makes the buying decision and how the customer purchases the process. The approach to prospective customers can be done by making a direct visit, telephone call, email or letter.

3. Product presentations, at this stage salesperson need to tell their products to prospective customers by showing the reasons and ways in which products can help resolve customer problems, this can be done using the FABV approach, namely features, advantages, benefits and value.

4. Convincing customers, at this stage salesperson need to look for objections that customers feel. Salesperson need to use a positive approach, asking customers to clarify perceived objections by giving questions such that customers answer their objections or turn them into reasons to buy.

5. Transactions, at this stage the sales force directs the customer to place an order and close the sale. Salesperson need to offer a certain boost to get a sale closing, such as additional services, additional amounts, or other prizes.

6. Maintaining relationships, this step is done to ensure customer satisfaction and clarify all the problems that the customer might have. After transactions, after the transaction, the salesperson follows up to ensure that the service is chosen according to the needs and desires of the customer, and maintains good relations with the customer.

\section{B. Promotional Material}

According to Lovelock \& Wirtz (2016)[6], corporate design roles such as consistent use of colors and graphic elements, appearance and design of promotional materials. Contribute to the impression in the customer's mind, strengthen or conflict with the content of the communication message conveyed by the company. Submitting messages to consumers needs to determine the content, structure, and style of messages that will be communicated, how they are presented, and the media that is best suited to reach the intended consumers. Advertising and display of promotional material with a consistent visual element can lead to smoothness and message preferences in the minds of prospective consumers; Visual themes that are in line with consumer expectations can also cause positive effects, they like the appearance of advertisements and the display of promotional materials when brand evaluations[9].

According to Belch \& Belch (2018) [5], the marketing division needs promotional materials that can be used by salesperson to attract customers, one of which is brochures. Using brochures is part of the IMC program that is under the control of marketers. Brochures can be used to convince buyers and convince buyers to make their decisions. Brochure display must have design and communication criteria to be more attractive to potential consumers, so that it is effective to communicate with the offerings submitted[10]. 
Developing print advertisements such as brochures need to pay attention to the basic components of print advertising such as bodies, headlines, visual styles and executions, and layouts. The headlines are the words that will be read first or positioned to attract the most attention. The headlines serve to entice readers to read the message want to convey by the company, the visual part of an advertisement clearly become an important part. Display visual elements often become the dominant part in print advertisements and play an important role in determining the effectiveness of ads[5].

The visual part of an advertisement must attract attention, communicate ideas or images, and work synergistically with the title and content of information to produce effective messages. The layout is a physical arrangement of various parts of the advertisement, including the main headline, subtitle, contents of information, illustrations, and any identification. The layout shows where each part of the ad will be placed and provides guidance to the people who are working on the ads[5].

\section{Methodology}

This business coaching study is a case study research using qualitative methods. There are 10 business coaching program sessions at MSME X. The first session began in November 2018 in one of the ballroom operated by MSME $\mathrm{X}$ located in the Grand Galaxy Bekasi. The second to fifth sessions have been conducted from December 2018 to February 2019 to analyze the company's business conditions and to identify problems. The seventh to tenth sessions have been conducted from March to May to implement solutions based on identified problems.

\section{A. Method of Collecting Data}

This study uses qualitative research methods, namely an approach that uses data in the form of written or oral sentences, phenomena, behaviors, events, knowledge and objects of study that can be observed by researchers. The implementation of business coaching uses several types of data, namely primary and secondary data. Primary data collection techniques use interviews to obtain complete data from informants, namely business owners and MSME $\mathrm{X}$ employees regarding the overall picture of the current business[11].

The method of interviewing is done by asking questions directly and openly to informants about problems related to research. The interview was conducted with Rika as the owner and director to ask about the business conditions of the MSME $\mathrm{X}$ as a whole. In addition, an interview with Risma was conducted to ask about marketing activities and Vera to ask about the administration of MSME X. The results of this interview will be part of the process of identifying company problems.

Furthermore, using the observation method, data collection is done by observing the object of research directly and recording the facts found in the field to complete the data relating to the problem. Observation also makes it easy to identify problems. In terms of secondary data collection, a literature study was conducted to obtain information and knowledge about the wedding services and to get the best solutions for problems solving. Literature studies are obtained from various sources such as scientific articles, journals, and other sources.

\section{B. Data Analysis Method}

The collected data were analyzed using six analysis tools, such as PESTLE Analysis, market opportunity analysis, competitor analysis, analysis of the business model canvas (BMC), marketing mix analysis and SWOT analysis. After carrying out the analysis, the final step is to draw conclusions from all data obtained. Conclusions are obtained by understanding the data that has been presented and used as information for business coaching purposes.

\section{1) PESTLE Analysis}

Understanding the external factors that have an impact on a company can be done using PESTLE analysis, the factors in PESTLE analysis include Politic, Economy, Social, Technology, Legal, and Environmental[12].

2) Market Opportunity Analysis

Market opportunities can be determined using analytical tools namely Segmenting, Targeting, and Positioning (STP). Careful analysis of the market must lead to market opportunities. Determine a profitable target market, where companies believe that customer needs and opportunities are not met, and where companies can compete effectively [5].

3) Competitor Analysis

According to Porter (2008)[13], a five forces analysis is a framework used to analyze the level of competition in industry and the development of business strategies. This analysis assumes that industrial attractiveness, in which companies operate, is determined by market structure because of the reason that market structures influence the behavior of market participants[14]. The five key factors used by the analysis to identify and evaluate potential opportunities and risks are threats of new entrants; threat of threat of substitutes; bargaining power of suppliers; the power of bargaining power of customers; competitive rivalry.

\section{4) Business Model Canvas Analysis (BMC)}

The canvas model business (BMC) is a tool that can be used to visualize the design of existing business models or redesign potential business models on one page. BMC contains nine basic building blocks and visualizes the logic of how organizations create, give and capture value, covering four main areas of business, namely, customers, value offerings, infrastructure and financial feasibility[15].

\section{5) Service Marketing Mix}

Marketers usually use four basic strategic elements when marketing physical goods, namely products, prices, places, and promotions. Lovelock \& Wirtz (2016) [6] develops 
additional elements in the marketing mix to deal with problems arising from marketing services or services by adding three other elements, namely processes, people involved in people processes and physical evidence, these seven elements are called as "7 P" from service marketing.

6) SWOT Analysis

SWOT analysis is a tool used to measure the elements of a company's strengths and weaknesses, its market opportunities, and external threats to its welfare in the future. Based on the results of the SWOT analysis, the TOWS matrix can then be used to deduce strategies that can be applied to find competitive advantage[12].

\section{RESUlT AND DISCUSSION}

\section{A. Analysis Results}

\section{1) PESTLE Analysis}

Based on the results of the PESTLE analysis of the six external factors, there are external factors that can become opportunities and pose a threat to MSME X.

Political factors pose a threat to MSME X, tax reduction policies imposed by the government open up the possibility of increasing competitors in the marriage industry.

The economic growth rate (LPE) of Bekasi City over a period of four years tends to move dynamically. LPE is one indicator of the success of development from the efficiency aspect initiated by the government. The higher the LPE, the better there will be an improvement in development in the regional economic sectors. This economic condition is an opportunity for MSMEs X located in Bekasi City.

Throughout 2017, data from the Badan Pusat Statistik (2018)[16], show there are 16,339 marriages in Bekasi City. MSME $\mathrm{X}$ is a MSME engaged in the field of marriage, the growth of marital numbers is an opportunity for the company's business continuity.

The development of technology raises a variety of new things, one of which is a marketplace site that provides a variety of wedding vendor services. The use of these sites can be utilized by MSME X to reach a wider market, make sales, and communicate with prospective customers.

Legal factors also pose a threat to the sustainability of MSME X businesses, Bekasi City has the second highest minimum wage rate (UMK) in West Java Province, even exceeding DKI Jakarta. In 2019, the UMK of Bekasi City experienced an increase of $8 \%$ from 2018. The increase in MSEs was a threat to SMEs $X$ because it could increase the cost of employee salaries borne by the company.

\section{2) Market Opportunity Analysis}

Consumers owned by MSME X demographically are individuals of all ages or men who come from the middle to upper class economy, geographically located in Jakarta, Bogor, Tangerang, Depok, and Bekasi. Behavioral, namely individuals who need a ballroom for weddings with a luxurious appearance, easily accessible locations, large capacity, and provide services for the overall event needs. Based on psychographic consumers who want prestigious ballroom rental at affordable prices and provide convenience in organizing the event.

MSME X's positions as a ballroom for weddings services that have a luxurious appearance by prioritizing excellent facilities and competitive prices. In addition, the company provides a one-stop service to facilitate consumers in organizing weddings. The appropriate strategy is the best cost provider strategy. This strategy is carried out by satisfying the buyers' desire for added value and imposing a lower price compared to competitors with similar product offerings[12].

3) Competitor Analysis

The competition intensity of the wedding industry similar to MSME $\mathrm{X}$ has moderate to high industrial interest. The threat of substitute products in this industry is high, because of the large number and variety of substitute products that consumers can use to hold weddings. The level of revalence in this industry tends to be high, this is due to the high competition of promotional activities carried out between companies to obtain consumers. Competition from the threat of new entrants, bargaining power of suppliers, and bargaining power of buyers is low. MSME X has a great opportunity to develop its business by expanding promotional activities to attract consumers.

4) Analysis of Business Model Canvas (BMC)

The picture below shows the business of MSME X's canvas model:

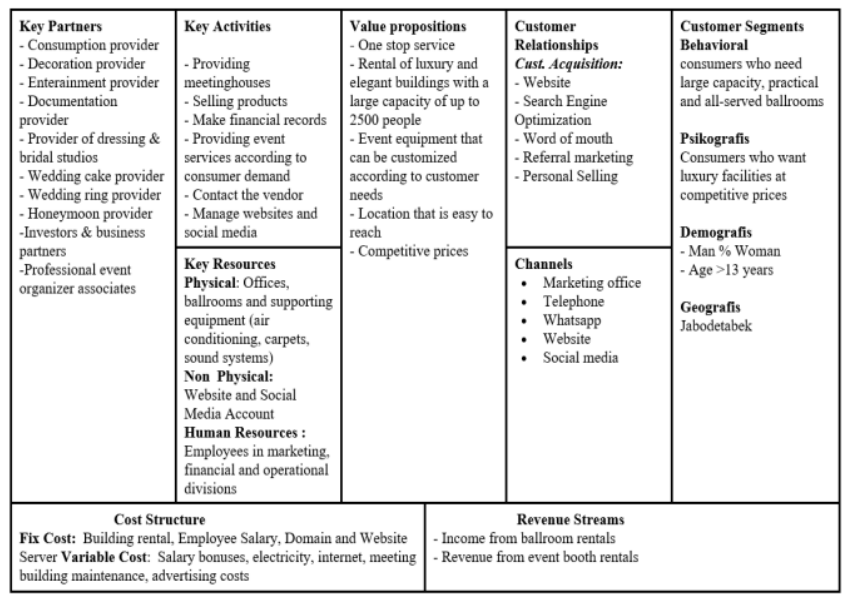

Figure 1. MSME X's canvas model

The results of the business analysis of the MSME X canvas model show that the consumer segments based on behavior, namely individuals who need a ballroom to hold large-capacity, practical and all-serving weddings. Based on psychographics, consumers who want luxury facilities at competitive prices. Based on demographics, male and female consumers aged over 17 years. The company geographically reaches customer segments in the Jakarta, Bogor, Depok, Tangerang and Bekasi areas.

The value proposition of the company is a luxurious ballroom and an elegant atmosphere, large-capacity with equipment that can be adjusted according to consumer 
needs and an easily accessible location with various toll road access facilities.

MSME $\mathrm{X}$ provides the marketing office to reach customers, customers can come directly to see the ballroom and feel the value offered by the company. The company has marketing employees to reach customers using the phone. In addition, MSME $\mathrm{X}$ has a website and uses social media to reach customer segments.

MSME $\mathrm{X}$ builds relationships with each customer segment, based on customer acquisition motivation, through a website that provides information about the products offered, location plans, prices and contact marketing division.

MSME $X$ revenue stream is obtained from ballroom rental services from wedding services customers and from partner vendors who rent booths when events.

Resources owned by MSME X are divided into physical and human resources. Physical resources consist of offices, ballroom and supporting equipment for organizing events (air conditioning, carpets, sound systems). While human resources are employees in the marketing, financial and operational divisions.

The key activity carried out by MSME $\mathrm{X}$ is to provide ballrooms, marketing employees will receive messages from consumers and then communicate and help provide event services according to customer requests. Salesperson will contact partners (vendors) to ensure customer needs are met as they wish, professional event management services are also carried out to ensure the event takes place in accordance with the wishes of the customer.

In order to maintain or enhance the value proposition, MSMEs X need to optimize resources to be able to produce quality performance, one of which is the performance of human resources, especially in the field of marketing can be improved. Wedding service sales activities have not been done optimally, this is because the competency level of employee sales is low and there is no personal selling standard among marketing employees.

The costs required by MSME X to run a business consist of fixed costs and variable costs. The fixed costs needed by the company in a certain period are website usage and ballroom rental costs. Ballrooms used in business enterprises are not owned by MSME $\mathrm{X}$, so to run a wedding service business, the company needs to spend a ballroom rental each year. Variable costs paid proportionally according to business activities include salary expense, electricity, internet, advertisements and ballrooms.

MSME $\mathrm{X}$ in its business process has a variety of partners (vendors) to serve customer needs at wedding services. Various partner choices are added value offered by the company, with a variety of partner choices, customers can easily fulfill the needs and desires of wedding events.

5) Service Marketing Mix

Product, MSME X offers ballroom rentals for weddings and professional event management services. The advantage of the company is providing a one-stop service to facilitate consumers by providing a number of package options that adapt to the needs and desires of consumers.

Price, MSME X offers its products in a package with options that can be tailored to the wishes and consumer's budget

Place, The location of the ballroom is quite strategic, located on the second floor of the Grand Galaxy Park Mall, in the residential area of Grand Galaxy City. MSME X can be accessed easily because it is close to various toll accesses.

Promotion, MSMEs $\mathrm{X}$ uses several promotional mix tools including personal selling, sales promotion to promote products and increase sales by giving prizes, and holding wedding exhibitions that have taken place six times.

Process, Business process of MSME X starts from receiving messages delivered by consumers who are interested in company services. The salesperson will receive messages, make sales and serve consumers until the event is completed.

People, MSMEs $\mathrm{X}$ has 13 employees, divided into several divisions, namely marketing and operations, finance, and human resources. The marketing division's employees are in charge of handling the entire sales activities, from prospecting, qualifying, presentation, closing and customer service.

Physical Evidence, MSME X has a ballroom with a capacity of up to 2000-2500 people with a luxurious look and elegant atmosphere, a ballroom equipped with carpets, air conditioners, good lighting and a maximum sound system. In addition, equipment in the ballroom can be adjusted with vendor assistance in accordance with consumer needs.

6) SWOT Analysis

Based on the SWOT Analysis, the figure below illustrates the TOWS Matrix of MSME X:

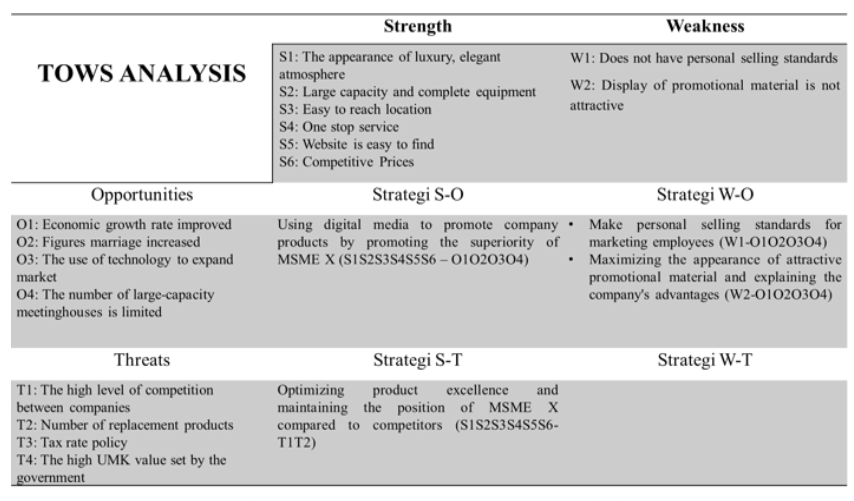

Figure 2. MSME X's canvas model

Based on the TOWS matrix, the solutions that can be done by MSME X are W1-O1O2, W2-O1O2 and S1S2O1O2, namely making effective personal selling standards by highlighting the superiority of services from MSME X 
and maximizing the appearance of attractive promotional material and explaining the company's superiority.

\section{B. Discussion of Solution Implementation}

1) Strandard of Personal Selling For Wedding Services

Based on the business coaching activities that have been conducted on MSME $X$, the following is the implementation of solutions to problems that have been analyzed in the form of operational standards in conducting personal selling activities for the sale of wedding services. The researcher used the effective personal selling framework from Antczak \& Sypniewska (2017)[7], in order to make a personal selling standard for the sale of MSME X wedding services, namely as follows:

a. Stages of Attracting Customers

At this stage customer qualifications need to be carried out by asking a number of questions which include the budget needed, the authority to buy, the need for a product or service and ensuring the use of the product or service[7].

The first step taken by MSME X marketing employees is to say hello, introduce the name and introduce yourself as a wedding consultant. After that, ask what can be helped, estimate the date of the event, and plan the number of invited guests. After knowing the information from prospective customers, the wedding consultant will confirm the availability of venues and packages for the number of invited guests who have been selected.

The wedding consultant provides information that the available package is all-in and can be tailored to the needs and desires of consumers. In addition, it is also informed that MSME X has a large selection of vendors to fulfill the wishes of prospective customers and families. At the end, the wedding consultant asked where the prospective customers get information about MSME X.

b. Stages of Conversation / Conducting Meetings

At this stage, marketing employees need to know the characteristics and needs of prospective customers [7]. This stage the wedding consultant asks consumers that the wedding event will be held is the wedding event to the consumer's family, this is done to find out the experience of the consumer's family. Wedding consultants also ask for plans for the concept of consumer weddings (National or International) and inform that the MSME $\mathrm{X}$ provides many vendor options (entertainment, catering, decoration, dressing studios, documentation) so that they can be customized as desired by prospective customers and families. For details, prospective customers are invited by wedding consultants to visit the MSME $X$ location in order to experience the wedding atmosphere there. The wedding consultant asked for a plan for the time the prospective customer came to visit the MSME X for a survey and learned more detailed information.

c. Product Presentation Stages

At this stage marketing employees need to tell and show that the product can help solve the problems of prospective customers, can use features, advantages, benefits and value approaches[7].

The wedding consultant met directly with prospective customers to explain the features of the company. The advantages and benefits of MSME $\mathrm{X}$ are also explained by the wedding consultant that MSME $\mathrm{X}$ is the best convention hall with facilities in Bekasi. The benefit is that MSME X makes it easy for its customers because it has an all-inclusive package. Wedding consultants need to remind the value of MSME $X$, that the price and condition of the ballroom offered is the best price and best value wedding services in Bekasi.

d. Stages of Convincing Customers

Consumers may have psychological and logical resistance[8], therefore wedding consultants need to take a positive approach to prospective customers. If potential customers are concerned about the price, wedding consultants can offer sales promotion by mentioning the overall value of the prize that the prospective customer will get. At this stage, wedding consultants have to assure all the problems that are feared by prospective customers.

e. Stage of Transactions

Antczak \& Sypniewska (2017)[7], explaining that at this stage it is necessary to direct potential customers to place orders and close sales. Wedding consultant explained the ease of payment offered by MSME X such as payment terms can be paid in installments after paying down payment (DP). Sales promotions that have been previously offered, need to be explained that the promo is only valid for a limited time, this is to encourage prospective customers to place an order. Wedding consultant informs that the promo will be lost if the customer does not immediately place an order by paying a down payment.

f. Stages of Maintaining Relationships

This stage is to ensure customer satisfaction and clarify all the problems that customers may have. Wedding consultants help develop customers in vendor selection, prepared order documents that will be confirmed by the customer. After the event takes place, the customer is given a feedback form that is useful for knowing customer satisfaction and input for MSME X.

\section{2) Promotional Material Display}

After conducting discussions with marketing owners and employees and making direct observations, in the process of personal selling MSME X marketing employees used promotional tools in the form of offer brochures. The display of promotional material offered by MSME $\mathrm{X}$ is considered not optimal in attracting consumers to purchase products, this is because the display of the offered brochure does not yet have the appearance and information that attracts consumers.

The offer brochure is designed with the use of gold, dark blue and white in accordance with the guidelines for using MSME X colors. Brochures measuring the size of A4 paper are $21 \mathrm{~cm} \times 29.7 \mathrm{~cm}$ and can be folded into 3 sides, 
the advantages of brochures of this size are many pages and small shapes that are easily carried by consumers. The layout of all components in the brochure is arranged with a design that is concise and easily understood by the recipient of the message.

The first page of the offering brochure displays the main headline which indirectly conveys information on elegant and pleasant wedding services, this page contains the MSME X logo, photos of couples who are married at the MSME X ballroom, company slogans and MSME X website addresses. Visual appearance becomes the dominant part in the offering brochure, the selection of photos and information content is used to communicate the company's strengths compared to competitors. On the first page, information about the role of the wedding consultant and the superiority of facilities and vendor choices from the MSME X are displayed, this is useful to produce messages that are effective in the minds of consumers.

The second page in the brochure displays information about the profile of MSME X containing product excellence such as a large capacity of up to 2500 people, architectural design that provides an elegant and magnificent atmosphere, There is a phrase "One Stop Wedding Solution" to show the services provided by MSMEs that include everything needed by consumers in holding weddings.

Information about service components is displayed using illustrations to make it easier for consumers to read and understand the various types of service components offered. Furthermore, there is one side that informs the company's contact, this side contains the office telephone number and marketing employees, the website address to the address and map of the MSME $\mathrm{X}$ to make it easier for consumers to contact the company.

\section{CONCLUSION}

Based on the results of research from business coaching it can be concluded that in designing personal selling standards companies can use theories that are adapted according to the company's business processes. Personal selling standards are used as a tool to solve the limitations of sales employees marketing skills, the standard used is displayed in the form of workflows to facilitate understanding of employees.

The use of personal selling standards needs to be applied consistently and periodically evaluated to maintain the quality of service and sales of the company. Improving the display of promotional material in the form of brochures, need to pay attention to the basic components of print advertising such as bodies, headlines, visual styles and executions, and layout. By repairing consumer brochures assessing MSME $\mathrm{X}$ to be more professional, the information obtained by consumers becomes more attractive and gives a positive impression in the minds of consumers. Display brochures that are designed professionally and convey information clearly can attract consumers to contact the company and provide a good impression in the minds of consumers.

\section{REFERENCES}

[1] Y. Sudaryo and D. Purnamasari, "Strategy development micro small and medium business performance in Small and Medium Enterprises (SMEs) Cibaduyut Shoe Bandung," Int. J. Sci. Technol. Res., vol. 6, no. 3, pp. 102-105, 2017.

[2] J. Obi et al., "Contribution of small and medium enterprises to economic development: Evidence from a transiting economy," Data Br., vol. 18, pp. 835-839, Jun. 2018.

[3] N. Ndiaye, L. A. Razak, R. Nagayev, and A. Ng, "Demystifying small and medium enterprises' (SMEs) performance in emerging and developing economies," Borsa Istanbul Rev., vol. 18, no. 4, pp. 269-281, 2018.

[4] Badan Pusat Statistik, Statistik Indonesia 2018. Jakarta: Badan Pusat Statistik, 2018.

[5] G. E. Belch and M. A. Belch, Advertising And Promotion: An Integrated Marketing Communications Perspective, Eleventh e. New York: McGraw-Hill Education, 2018.

[6] J. Wirtz and C. Lovelock, Services Marketing. Singapore : World Scientific Publishing Company, 2016.

[7] A. Antczak and B. A. Sypniewska, Cross-Cultural Personal Selling: Agents' Competences in International Personal Selling of Services. Cham Springer International Publishing Palgrave Macmillan, 2018.

[8] P. Kotler and K. L. Keller, Marketing Management, 15th ed. Boston: Pearson, 2016.

[9] B. J. Phillips, E. F. McQuarrie, and W. G. Griffin, "How visual brand Identity shapes consumer response," Psychol. Mark., vol. 31, no. 3, pp. 225-236, Mar. 2014.

[10] P. Q. Brito and J. Pratas, "Tourism brochures: Linking message strategies, tactics and brand destination attributes," Tour. Manag., vol. 48, pp. 123-138, Jun. 2015.

[11] H. Arini, B. Badarrudin, and K. Kariono, "Efektivitas inkubator bisnis dalam pelaksanaan pembinaan usaha masyarakat kecil menegah," J. Adm. Publil, vol. 8, no. 1, pp. 1-17, Jun. 2018.

[12] A. A. Thompson, M. A. Peteraf, J. E. Gamble, and A. J. Strickland, Crafting \&amp; Executing Strategy: The Quest For Competitive Advantage,Concepts And Cases. New York: McGraw-Hill Education, 2018.

[13] M. Porter, The Five Competitive Forces that Shape Strategy. Tampa, Florida: Harvard Business Review, 2008.

[14] M. Raible, "Industrial organization theory and its contribution to decision-making in purchasing," in 2nd IBA Bachelor Thesis Conference, 2013.

[15] A. Osterwalder and Y. Pigneur, Business Model Generation. New Jersey: John Wiley \& Sons, Inc, 2010.

[16] Badan Pusat Statistika Bekasi, Kota Bekasi Dalam Angka 2018. Bekasi: Badan Pusat Statistika Bekasi, 2018. 